\title{
THE LOGIC OF EXCESS
}

Helen Piers, Mouse Looks for a House

It's hard for a mouse

to find a house

that's not too cold, not too hot, not too big, not too small, not too noisy, not too wet, not too dirty.

For Claire, Rupert, Wolfgang and Torben who found a house.

\section{Looking for a House, and other Excess Avoidance Exercises}

For whatever reason, you want to find and move into a new house. At once you are faced with a multidimensional exercise in avoiding excesses. The house should be large enough for your needs, but not so large that it is too expensive to run or furnish; it should be close enough to your workplace, and that of your partner, and to good schools for your children, and to transport connections. It should be light enough, well enough insulated, well enough served with utilities, and in good enough condition, and above all, it should not be too expensive. When my children were small, they enjoyed, both in English and in German, Helen Piers's little book about a mouse looking for a house, which encapsulates, in miniature form, the problems of avoiding excesses in finding a house.

In everyday life we are surrounded by the need to avoid practical excesses. One should eat enough fruit, but not too much fatty food, drink 
enough fluids, but not too much alcohol, not drive too fast, allow enough time to get to the airport, pack enough clothes for the holiday but not so many as to incur excess baggage charges, be neither overweight nor underweight, get enough exercise and enough sleep, and so on.

This paper is a little exercise in a micrologic, the logic - philosophical and formal - of excess (too much), its obverse (too little = not enough), and their contradictories (not too much, not too little = enough).

\section{The Excess Square of Opposition}

One big clue that there is a logic to be found here is that the formal terms of the logic of excess ${ }^{1}$ form a square of opposition, like in any self-respecting logic. Let us for now fix the dimension of variation, call it just ' $X$ '. Then the square of opposition looks like this:

Too much $X$

$=$ Excessive $X$

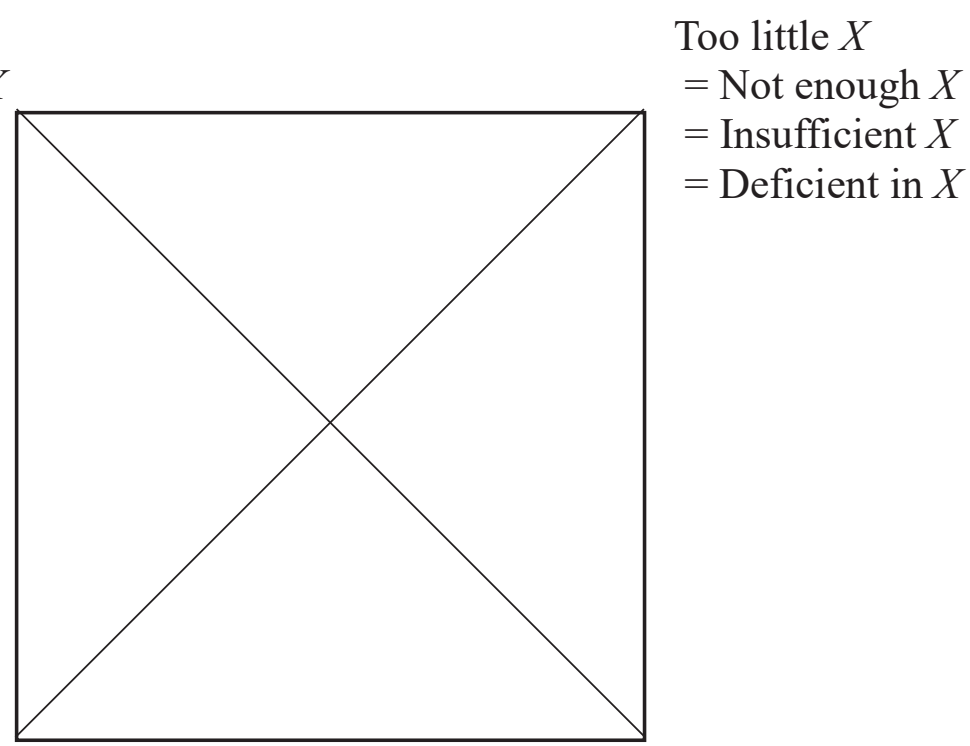

Not too much $X$ $=$ Not excessive $X$

Enough $X=$

Sufficient $X=$

Not too little $X$

${ }^{1}$ I shall call it this for brevity: a fuller but less mellifluous name would be 'the logic of excess and sufficiency'. 
Whenever we have a square of opposition, there are three mutually exclusive "statuses" involved, two "extremes" or "major" statuses, and one "middle" or intermediate status, which is the conjunction of the two "minor" statuses. In the categorical square they are All, No, and Some but not all; in the modal square they are Necessary, Impossible, and Contingent (= Possible but not necessary); in the deontic square they are Obligatory, Forbidden, and Optional (= Permitted but not obligatory); here they are Too much, Too little, and Enough but not too much. To have a short name for this last status I shall call it Suitable. As almost always happens with squares of opposition, it is the lower right corner, the ' $\mathrm{O}$ '-corner, that is least likely to be unitarily lexicalised, i.e. to have its own single term. Avoiding excesses in a given case means steering for a place in the intermediate or suitable zone. This is sometimes called the "comfort zone", and in some cases indeed the "Goldilocks zone". ${ }^{2}$

Where there is a square of opposition, there is also a hexagon of opposition. ${ }^{3}$ In our case this comes from admitting the status Unsuitable, which is the disjunction either too much or too little, and is contradictory to Suitable. Later we shall mention the last two terms completing the full octagon of opposition.

\section{Dimensions of Variation}

As our opening examples indicate, there are many dimensions of variation, concerning which particular cases may be excessive or sufficient. Some have to do with kinds of quality, such as wetness or dryness, some with values, such as utility or comfort, some with quantity kinds such as weight, length, social goods such as income and wealth, or with kinds of relation, such as proximity. Aristotle's account of the Golden Mean is about seeking to exemplify virtues which avoid contrary excesses, proper courage being the suitable mean between too little braveness (cowardliness) and too much braveness (recklessness). What they all have in common however, is that they are in some way or another quantifiable. If $X$ is a dimension of variation, it must be possible to say that one case or instance is more or less $X$ than another, or that they are $X$ to the same degree or extent.

${ }^{2}$ In the English fairy tale, Goldilocks found the bears' porridge that was neither too hot nor too cold, their chair and bed that were neither too hard nor too soft. Those suitable things in the comfort or Goldilocks zone are "just right". Planets in the Goldilocks zone - more scientifically, the circumstellar habitable zone or CHZ - around a star are not too far from it and not too near to it for there to be liquid water on its surface, and so to be able to support life as we know it.

${ }^{3}$ On hexagons (and octagons) in modal logic and more generally, see (Simons 2012). 
The nature of this quantification need not be scientifically exact. Not all quantities are isomorphically represented by the non-negative real numbers, though of course some are. The lengths of air routes between one airport and another form a distance continuum. For an aircraft with a given maximum range for a given payload, some routes are too long to fly. In some circumstances, a merely ordinal scale will work. The Mohs Hardness Scale for minerals is an ordinal scale. For some purposes, for example, finding a suitably scratch-resistant surface for a kitchen top, one may be looking for a mineral with hardness of at least 5 but not greater than 7 . So anywhere between 5 and 7 inclusive is suitable, one of hardness 4 or less is too soft, and one of hardness 8 or more is too hard. Nor need the quantities in question always be mathematically exact. The walking distance from my front door to the nearest railway station is around 1.3 $\mathrm{km}$, an approximate distance, not an exact distance measurable to atomic precision.

Dimensions of variation $X$ for which we may speak of some things being more or less $X$ than other things typically select one preferred direction of variation as being "increasing" and the opposite direction as being "decreasing", and the generic name for the determinable dimension of variation, with its different determinate values or degrees, is often the same as or cognate with the name for the positive direction. When asking about the length of an object, we ask "How long is it?" The term for the dimension, 'length', is cognate to 'long'. It requires a special setting, for example when trying to fit an object into a confined space, for us to switch to asking, "How short is it?" In linguistic parlance, of the two opposed terms, 'long' and 'short', it is 'long' that is the unmarked term and 'short' that is the marked term. Likewise, when asking about the weight of a body, for example, we naturally ask "How heavy is it?" The "positive" direction is here towards the heavier, and objects significantly far along that spectrum are called "heavy". Again, it would take a special setting for us to switch to the marked term and ask, "How light is it?"

Where $X$ is a dimension of variation, items $a$ and $b$ can be such that $b$ is more $X$ than $a$. Since this is a relation, it has a converse: $a$ is less $X$ than $b$. But in the light of distinctions between polar opposites like long/short, near/far, heavy/light, old/young etc., it would be good to have an operation taking $X$ to the reversed comparison. We co-opt the general reversing prefix 'un-' for an operator taking the direction of increasing $X$ to the direction of decreasing $X$, and say that less $X=$ more un- $X$ : to be younger is to be less old, that is, more un-old. This is not linguistically pretty, but it allows us to generalise. There are some precedents in natural language. To be unhappy is to be the opposite of happy. Polar opposites normally do not exhaust their range; they leave an intermediate area. In this case, to be 
unhappy is to be more than just not happy: it is to be, as is sometimes said, "positively unhappy". To be in the intermediate zone is to be neither happy nor unhappy. We will write ' $u X$ ' for ' $u n-X$ '. This polar or directional reversal is obviously of period two: $u \mathrm{u} X=X$.

\section{The Form of Statements of Excess}

Again, we will keep the dimension of variation $X$ fixed but indefinite. The general form of statements about excess etc. is taken to be

$a$ is $\mathbf{K}$ in $X$ in order that $p(a)$

where $X$ is the dimension of variation, ' $a$ ' names an object, person, situation etc. which has $X$ to some degree, which I shall call the subject of the statement, ' $K$ ' stands in for the specific terms of the logic, like 'too much', 'enough', 'not enough' etc., and ' $p(a)^{\prime}$ 'stands in for a sentence that states some aim, requirement or desideratum, one which concerns $a$ in some way or another, and which I shall refer to as the goal. To get the flavour, here are some examples, which we regiment in this form.

This house is too expensive for me to buy

comes out as

This house is too much in price in order that I buy it

Here $a=$ this house, $\mathbf{K}=$ too much, $X=$ price, and $p(a)=\mathrm{I}$ buy this house.

Jim is not old enough to enlist in the Navy

Jim is not enough in age in order that he enlist in the Navy

$a=\mathrm{Jim}, \mathbf{K}=$ not enough, $X=$ age, $p(a)=$ Jim enlists in the Navy

We can put the same fact another way:

Jim is too young to enlist in the Navy

Here, $a=$ Jim, $\mathbf{K}=$ too much, $X=$ youth (un-age), $p(a)=$ Jim enlists in the Navy

The economy has grown enough for the Finance Minister to cut taxes [sc. without damaging the economy]

$a=$ the economy, $\mathbf{K}=$ enough, $X=$ growth, $p(a)=$ the Finance Minister cuts taxes without damaging the economy

A final example:

The Earth is suitably far from the Sun to support life

$a=$ the Earth, $\mathbf{K}=$ suitable (not too much and not too little), $X=$ distance from the Sun,

$p(a)=$ the Earth supports life. That is, the Earth is in the CHZ or Goldilocks zone. 
To express all we need, the following letters are used for the values of ' $K$ ':

E Excessive, too much

D Deficient, too little

G Enough, sufficient (cf. German Genügend)

S Suitable

U Unsuitable

C Not too much (the Cinderella corner)

The shape of formulas we will adopt for statements of these kinds is

$a \mathbf{K}_{X} p(a)$

and for comparisons in dimension $X$ we use $a \leq_{X} b$ in the obvious manner, with the principles of a linear order applying to $a \leq_{X} b$, which are set out explicitly in Section 10 below.

\section{Modalities and Implicatures}

The concepts of excess, sufficiency etc. are intrinsically modal in nature. If any statement of the form $a \mathbf{E}_{X} p(a), a \mathbf{D}_{X}(a)$ or $a \mathbf{U}_{X} p(a)$ is true then not only is it not true that $p(a)$, but in some sense $p(a)$ cannot be true. If Jim is too young to join the Navy, or too old to join the Navy, then he cannot join the Navy. So it seems. But it was not uncommon for young boys to run away to sea, lie about their age, and join the $\mathrm{Navy}^{4}$, and it has been known for older men to pretend they are younger than they are in order to serve. The statement that Jim is too young to join the Navy certainly does not imply he cannot do so under any circumstances, or that it is logically or naturally impossible, but only that he cannot join legitimately, according to the rules. Such riders and qualifications are often left tacit in ordinary speech. Likewise, if we say that this gate is too narrow for me to drive my car through, that doesn't automatically entail that I do not. It may be too narrow for me to drive through without damaging my car or the gate, and that is what is normally meant, but that doesn't stop me from doing it if I intend to get through come what may, or if I make an error of judgment and drive through, scratching my car and/or demolishing the gatepost in the process.

The sense of "cannot" or "not possible" is one which in each case appropriate to the dimension of variation, the situation and the goal. If Jim is too young to join the Navy legitimately, but he lies about his age and joins anyway, he may have joined, but he still has not joined legitimately, and

${ }^{4}$ Recent genealogical research reveals that almost a third of seamen who served in the Royal Navy in World War I joined between the ages of 14 and 17, when the minimum age for seeing combat was 18 (Agency 2015). 
he could not. If my car is too wide to pass through the gate without damage, then even if it passes through, it cannot pass through without damage, and does not pass through without damage. Suppose Jim is old enough and young enough to join the Navy. It still does not follow that he can join the Navy: he might not be physically fit enough, he might not be of the requisite nationality, the Navy might not be recruiting. What we can say is that he can, as far as his age goes, join the Navy. The modal operator is therefore aligned with the dimension $X$. Writing ' $\diamond_{X}^{\prime}$ ' for 'it is possible as far as $X$ goes that', this means that all of the following can be asserted as theses of excess logic

$$
\begin{aligned}
& a \mathbf{E}_{X} p(a) \rightarrow \sim \diamond_{X} p(a) \\
& a \mathbf{D}_{X} p(a) \rightarrow \sim \diamond_{X} p(a) \\
& a \mathbf{U}_{X} p(a) \rightarrow \sim \diamond_{X} p(a)
\end{aligned}
$$

Contraposing, if Jim can or actually does join the Navy legitimately, then he must have been old enough to do so.

$$
\diamond_{X} p(a) \rightarrow a \mathrm{G}_{X} p(a)
$$

However, we cannot simply turn this round and assert

$$
a \mathbf{G}_{X} p(a) \rightarrow \diamond_{X} p(a)
$$

because even if Jim is old enough to join the Navy, for him to be able to join it, he must in addition not be too old to do so. He has to be both old and young enough to do so, which of course has the form

$$
a \mathbf{S}_{X} p(a) \rightarrow \diamond_{X} p(a)
$$

The converse implication also holds: if it is possible as far as his age goes for Jim to join the Navy then he must be old enough to do so but not too old to do so. More generally,

$$
\diamond_{X} p(a) \rightarrow a \mathbf{S}_{X} p(a)
$$

In terms of meaning, there appears to be little to choose between sentences overtly expressing the modality, and those that do not. For example

Mary is old enough to vote

does not differ significantly from

Mary is old enough to be able to vote

The connection between the local meaning of 'possible', and that of statements of satisfactoriness is indeed so close that I can see no point in 
separating them. Rather we shall understand ' $\diamond_{X} p(a)$ ' to mean the same as ' $a \mathbf{S}_{X} p(a)^{\prime}$ ': this delivers all the results one would wish, and it avoids an otherwise undefined concept.

In everyday speech, when we say "Jim is old enough to join the Navy" we often do imply that he can, without qualification. What has gone wrong here? The answer is that in everyday speech we frequently incur Gricean implicatures, that is, for pragmatic reasons we make additional conversational commitments beyond the logically strict form of our words. A typical example using a different logical form is

Some of those at the party drank vodka

which implicates - but does not logically entail - that some did not drink vodka. The lack of logical entailment is shown by the ability to cancel implicatures, so the following is not inconsistent:

Some of those at the party drank vodka; in fact, everyone there did.

Similarly, when we say

Jim is old enough to join the Navy

we normally implicate that he is not too old to do so, but the following is a consistent - if conversationally unlikely - thing to say:

Jim is old enough to join the Navy; in fact, he's too old to do so.

When dealing with the logic of the $\mathbf{G}$ and $\mathbf{C}$ forms, we shall be logically strict, and ignore possible implicatures.

It is worth stressing that non-modal implications such as

$$
a \mathbf{S}_{X} p(a) \rightarrow p(a)
$$

cannot be affirmed, for the simple reason that just because something is possible does not mean it is actual. Jim might be of a suitable age to legitimately join the Navy, but simply not do so, either because he chooses another career, or for a debarring reason like those mentioned above.

Sometimes, especially when using the past tense, statements of sufficiency imply or hint that the goal was not just possible, but was actually attained. This can be the case for example with

In 1914, Jim was old enough to join the Navy

But while we often infer from the making of such a statement that Jim did in fact join the Navy, it does not strictly follow that he did. If we add a second statement, the assumption can be confirmed:

In 1914, Jim was old enough to join the Navy. He went on to fight at Jutland.

The second statement makes it clear to the historically informed that he did join (the Battle of Jutland was a naval engagement of 1916), but the first statement could have been followed differently:

In 1914, Jim was old enough to join the Navy. He chose to join the Army instead. 
Whenever a vernacular G, C or S statement implies or hints that the goal was actually achieved, it is best to make that explicit, as in

$$
a \mathbf{G}_{X} p(a) \wedge p(a)
$$

Finally, note the importance of having the subject $a$ included in the statement of the goal $p(a)$. To leave this out, and allow any sentence as expressing the goal is to invite irrelevant nonsense, such as

Jim is old enough for Fred to join the Navy

Jim is old enough for $2+2$ to equal 4

Jim is too young for $2+2$ to equal 5 .

\section{Different Subjects}

There are circumstances in which from one statement of excess or sufficiency, about a certain subject, we may validly infer another such statement about a different subject. For example

This house is too expensive for me to buy

That house is more expensive than this one

therefore

That house is too expensive for me to buy

Here is another example

Jim to too young to join the Navy

Fred is younger than Jim

therefore

Fred is too young to join the Navy

We may call this the principle of monotonicity of excess. It demonstrates how important it is to have the subject mentioned in the statement of the goal, allowing the insufficiency to be transferred.

\section{Thresholds}

If one house is too expensive for me to buy, but another one is not, then somewhere between their two prices there is a threshold price, below which I can afford a house, above which I cannot. Likewise, if Jim is old enough to join the Navy but Fred is too young to do so, then between their two ages there is a threshold age, below which one cannot join the Navy, above which one can (provided one is not too old). Such thresholds may be sharp or vague. In the case of legal thresholds, they tend to be sharp: one can only join the Royal Navy once one has reached the age of 16 years and 
not exceeded the age of 39 years. In other cases, they may be vague. There is no exact price above which I cannot afford a house: I might squeeze a little extra money from somewhere if I really want a house which is in the borderline price zone, but not if I am not so keen on it.

What we can say is that, whether a threshold is exact or not, the status of sufficiency on either side of the threshold is different. For quantities where there is both a minimum and a maximum, we have to be more specific. Before we can formulate the relevant principles we need to determine how the thresholds relate to $X$ and $p(\ldots)$, since they depend on both. This house may be too expensive for me, but not too large for me; it may be too expensive for me but not for someone else; it may be too expensive for me to buy, but no too expensive for me to rent; and this other house may not be too expensive for me to buy. We define the lower threshold of a dimension $X$ for $p$ as that value of $X$ below which the goal cannot be attained, and the upper threshold as that above which the goal cannot be attained. Formal definitions follow in Section 10.

We deliberately refrain from saying much about what happens if a subject's sufficiency etc. falls exactly on (or in) one of the thresholds: this will vary from case to case so it is better to treat cases on their merits, especially if the threshold is extended and vague.

There will not always be two thresholds. For a person without means, any house is too expensive, while for a billionaire, no car is too expensive. In Joseph Heller's novel Catch 22, no combatant is too insane to be excused combat duty. A theoretical limiting case is when the lower threshold and the upper threshold coincide. Imagine a perfect balance, which is in equilibrium only if the two objects on either side are exactly the same in weight. Suppose there is an object weighing exactly $100 \mathrm{~g}$ in one pan. For the balance to be in equilibrium, the object in the other pan must also weigh exactly $100 \mathrm{~g}$. If the second object weighs any less, the balance tips towards the first object, if it weighs any more, the balance tips towards the second. The zone of suitability is in this case reduced to a point. Whether such a wafer-thin case is actually possible in any real situation is not the point. All we require is that the cases of excess and deficiency do not overlap, even in a point. Nothing can be both too much and too little at the same time and in the same respect. We call this the principle of contrariety.

\section{Negative Goals}

We have yet to look at the relationship between a positive goal $p(a)$ and its negation $\sim p(a)$. This is not so straightforward as might appear. It takes a special context or type of variation for a negative goal to take precedence: in general, the positive is unmarked, the negative is marked. In 
Brazil, literate citizens aged between 18 and 70 are required to vote in elections, while those aged between 16 and 18, or over 70, may vote, but do not have to do so. We must distinguish then four age-voting statuses

João is not old enough to vote

João is old enough to vote but not old enough to have to vote

João is old and young enough to have to vote

João is too old to have to vote.

There are in Brazil different thresholds for being able to vote and for it being compulsory to vote. Suppose our citizen João dislikes voting, so he is "positively" interested in the ages when he is not required to vote. His thoughts might have the following English rendering:

Below the age of $18 \mathrm{I}$ am young enough not to have to vote and above the age of $70 \mathrm{I}$ am old enough not to have to vote, but between the ages of 18 and $70 \mathrm{I}$ am neither young enough nor old enough not to have to vote, so I then have to vote.

We have then the three zones

Young enough not to vote I Of an unsuitable age not to vote I Old enough not to vote or in notation

$$
a \mathbf{C}_{\text {age }} \sim(a \text { votes }) \mid a \mathbf{U}_{\text {age }} \sim(a \text { votes }) \mid a \mathbf{G}_{\text {age }} \sim(a \text { votes })
$$

The negative goal turns the landscape inside out. Whereas in the positive case the extreme zones represent compulsion and the middle zone represents permission, with a negative goal the extremes represent permission and the middle zone compulsion. One is never too young to not have to vote, and one is never too old to not have to vote. Because of the greater cognitive complexity of the negative case, we tend to accentuate the positive.

\section{Multiple Thresholds in One Dimension}

We can however get the positive and negative cases to work together. Given the duality between necessity and possibility, and given our definition of local possibility as

$$
\diamond_{X} p(a) \leftrightarrow a \mathbf{S}_{X} p(a)
$$

we can define the corresponding local necessity as

$$
\square_{X} p(a) \leftrightarrow \sim\left(a \mathbf{S}_{X} \sim p(a)\right)
$$


that is, as

$$
\square_{X} p(a) \leftrightarrow a \mathbf{U}_{X} \sim p(a)
$$

and we can utilise this to integrate different modal cases involving the same $X$ and $p(a)$ in a single dimension with up to four thresholds, using both positive and negative goals. Noting that, as usual

$$
\square_{X} p(a) \rightarrow \diamond_{X} p(a)
$$

any zone within which necessity or compulsion holds, call it the zone of inevitability, will have to be, in all non-trivial cases, a proper part of the zone of suitability.

As an example, imagine the Brazilian voting scheme modified so that citizens over 85 are forbidden to vote. We would then have four thresholds with the following five age zones.

\begin{tabular}{|l|l|l|}
\hline Age & Description & Formula \\
\hline $0-16$ & Too young to vote & $a \mathbf{D}_{\text {age }} a$ votes \\
\hline $16-18$ & Old enough to vote but not old enough to have to vote & $\begin{array}{l}a \mathbf{G}_{\text {age }} a \text { votes } \wedge \\
a \mathbf{C}_{\text {age }} \sim(a \text { votes })\end{array}$ \\
\hline $18-70$ & Of suitable age to have to vote $=$ Of unsuitable age to not vote & $a \mathbf{U}_{\text {age }} \sim(a$ votes $)$ \\
\hline $70-85$ & Not too old to vote but old enough not to have to vote & $\begin{array}{l}a \mathbf{C}_{\text {age }} a \text { votes } \wedge \\
a \mathbf{G}_{\text {age }} \sim(a \text { votes })\end{array}$ \\
\hline $85+$ & Too old to vote & $a \mathbf{E}_{\text {age }} a$ votes \\
\hline
\end{tabular}

\section{A Logic of Excess}

Axioms of Dimensions of Variation

$\exists b\left(a \leq_{X} b \vee b \leq_{X} a\right) \rightarrow a \leq_{X} a$

$a \leq_{X} b \wedge b \leq_{X} c \rightarrow a \leq_{X} c$

$a \leq_{X} a \wedge b \leq_{X} b \rightarrow a \leq_{X} b \vee b \leq_{X} a$

Axiom of Polar Reversal

$a \leq_{X} b \leftrightarrow b \leq_{\mathrm{uX}} a$

Axiom of Excess or Deficiency

$a \mathbf{E}_{X} p(a) \vee a \mathbf{E}_{\mathrm{uX}} p(a) \rightarrow \sim p(a)$ 
Axiom of Contrariety

$\sim\left(a \mathbf{E}_{X} p(a) \wedge a \mathbf{E}_{\mathrm{uX}} p(a)\right)$

Axiom of Monotonicity

$a \mathbf{E}_{X} p(a) \wedge a \leq_{X} b \rightarrow b \mathbf{E}_{X} p(b)$

Definitions for Dimensions of Variation

$a={ }_{X} b \leftrightarrow a \leq_{X} b \wedge b \leq_{X} a$

$a<_{X} b \leftrightarrow a \leq_{X} b \wedge \sim\left(b \leq_{X} a\right)$

Definitions of Constants of Excess and Sufficiency

$a \mathbf{D}_{X} p(a) \leftrightarrow a \mathbf{E}_{\mathrm{uX}} p(a)$

$a \mathbf{G}_{X} p(a) \leftrightarrow \sim\left(a \mathbf{D}_{X} p(a)\right)$

$a \mathbf{C}_{X} p(a) \leftrightarrow \sim\left(a \mathbf{E}_{X} p(a)\right)$

$a \mathbf{S}_{X} p(a) \leftrightarrow a \mathbf{G}_{X} p(a) \wedge a \mathbf{C}_{X} p(a)$

$a \mathbf{U}_{X} p(a) \leftrightarrow a \mathbf{E}_{X} p(a) \vee a \mathbf{D}_{X} p(a)$

There are two more constants we can define, the universal or tautologous $\mathbf{V}$, and the empty or contradictory $\Lambda$ :

$a \mathbf{V}_{X} p(a) \leftrightarrow a \mathbf{S}_{X} p(a) \vee a \mathbf{U}_{X} p(a)$

$a \Lambda_{X} p(a) \leftrightarrow a \mathbf{S}_{X} p(a) \wedge a \mathbf{U}_{X} p(a)$

and these complete the octagon of opposition of excess and sufficiency.

Definitions of Local Modalities

$\diamond_{X} p(a) \leftrightarrow a \mathbf{S}_{X} p(a)$

$\square_{X} p(a) \leftrightarrow \sim\left(a \mathbf{S}_{X} \sim p(a)\right)$

Definitions of Lower and Upper Thresholds

$\operatorname{Lth}(X, p)=1 z\left(\forall y\left(y<_{X} z \rightarrow y \mathbf{D}_{X} p(y)\right)\right)$

$\operatorname{Uth}(X, p)=1 z\left(\forall y\left(z<_{X} y \rightarrow y \mathbf{E}_{X} p(y)\right)\right)$

Strictly, since ' $p$ ' is a one-place predicate which can be complex, the definientia should have the forms

$\operatorname{Lth}(X, \lambda z \cdot p(z))$

$\mathrm{Uth}(X, \lambda z \cdot p(z))$

but for brevity the forms given are usually adequate.

\section{Some Theorems}

The proofs of the following theorems are elementary. The difficulty in the logic of excess is not that there are intricate proofs of unexpected results (at least, I think not), but that of getting the formulation of the basic ideas right. 


$\begin{array}{ll}a \leq_{X} b \leftrightarrow a \leq_{\mathrm{uuX}} b & \text { Double Reversal } \\ \sim\left(a \mathbf{E}_{X} p(a) \wedge a \mathbf{D}_{X} p(a)\right) & \text { Contrariety } \\ a \mathbf{E}_{X} p(a) \rightarrow \sim p(a) & \text { Excess } \\ a \mathbf{D}_{X} p(a) \rightarrow \sim p(a) & \text { Deficiency } \\ a \mathbf{U}_{X} p(a) \rightarrow \sim p(a) & \text { Unsuitability } \\ p(a) \rightarrow a \mathbf{G}_{X} p(a) & \text { Sufficiency } \\ p(a) \rightarrow a \mathbf{C}_{X} p(a) & \text { Non-Excess } \\ p(a) \rightarrow a \mathbf{S}_{X} p(a) & \text { Suitability } \\ a \mathbf{D}_{X} p(a) \wedge b \leq_{X} a \rightarrow b \mathbf{D}_{X} p(b) & \text { Converse Monotonicity } \\ a \mathbf{E}_{X} p(a) \rightarrow a \mathbf{G}_{X} p(a) & \text { Subalternation 1 } \\ a \mathbf{D}_{X} p(a) \rightarrow a \mathbf{C}_{X} p(a) & \text { Subalternation 2 } \\ a \mathbf{G}_{X} p(a) \leftrightarrow a \mathbf{C}_{\mathrm{uX}} p(a) & \text { Minor Obversion } \\ a \mathbf{G}_{X} p(a) \leftrightarrow \sim\left(a \mathbf{E}_{\mathrm{uX}} p(a)\right) & \text { Inner Duality 1 } \\ a \mathbf{C}_{X} p(a) \leftrightarrow \sim\left(a \mathbf{D}_{\mathrm{uX}} p(a)\right) & \text { Inner Duality 2 } \\ a \mathbf{U}_{X} \sim p(a) \rightarrow a \mathbf{S}_{X} p(a) & \text { Must } \rightarrow \text { May } \\ \square_{X} p(a) \rightarrow \diamond \diamond_{X} p(a) & \text { Modal Weakening } \\ & \end{array}$

\section{Models}

The requirements for representation in a model for this kind of statements are the following. We have a non-empty domain $D$ of subjects (the $a, b$ etc.), we have a dimension of variation $X$, and we have a predicate $p$ intended to be true or false of elements of the domain with respect to $X$.

We map values of $X$ to non-negative real numbers, $\mathbb{R}_{+0}$ by a map $M: D$ $\rightarrow \mathbb{R}_{+0}$ such that for all $a, b \in D, a \leq_{X} b \leftrightarrow M(a) \leq M(b)$. This ensures that the axioms for $X$ are adequately represented. Obviously $a \leq_{\mathrm{uX}} b \leftrightarrow M(b) \leq M(a)$. The image of $D$ under $M$ need not be the whole of $\mathbb{R}_{+0}$.

A predicate $p$ is mapped to a subset of $\mathbb{R}_{+0}$ by a valuation function $V$, which conforms to one of the following three cases, each with two subcases:

Case 1: For some $l \in \mathbb{R}_{+0^{\prime}}, V(p)=\left\{x \in \mathbb{R}_{+0}: x \geq l\right\}$

Subcase 1a: $l=0 . V(p)=\mathbb{R}_{+0}$

Subcase $1 \mathrm{~b}: l>0 . V(p)$ is a top segment of $\mathbb{R}_{+0}$

Case 2: For some $k \in \mathbb{R}_{+0^{\prime}} V(p)=k$

Subcase 2a: $k=0$

Subcase $2 \mathrm{~b}: k>0$

Case 3: For some $l, h \in \mathbb{R}_{+0}$ such that $l<h, V(p)=[l, h]=\left\{x \in \mathbb{R}_{+0}: l \leq x \leq h\right\}$ Subcase 3a: $l=0 . V(p)$ is an initial interval of $\mathbb{R}_{+0}$ Subcase 3b: $l>0 . V(p)$ is a medial interval of $\mathbb{R}_{+0}$. 
The numbers $l, h$ and $k$ are threshold values: $l$ for the lower threshold, $h$ for the upper threshold (if any), and $k$ for the limiting case where they coincide. Given $D, M$ and $V$, the truth conditions for basic statements of excess and sufficiency are then determined as follows:

In Case 1a

$a \mathbf{E}_{X} p(a)$ is always false

$a \mathbf{D}_{X} p(a)$ is always false

$a \mathbf{S}_{X} p(a)$ is always true

In Case $1 b$

$a \mathbf{E}_{X} p(a)$ is always false

$a \mathbf{D}_{X} p(a)$ is true for $V(a)<l$ and false for $V(a) \geq l$

$a \mathbf{S}_{X} p(a)$ is false for $V(a)<l$ and true for $V(a) \geq l$

In Case 2a

$a \mathbf{E}_{X} p(a)$ is true for $V(a)>0$ and false for $V(a)=0$

$a \mathbf{D}_{X} p(a)$ is always false

$a \mathbf{S}_{X} p(a)$ is true for $V(a)=0$ and false otherwise

In Case $2 b$

$a \mathbf{E}_{X} p(a)$ is true for $V(a)>k$ and false otherwise

$a \mathbf{D}_{X} p(a)$ is true for $V(a)<k$ and false otherwise

$a \mathbf{S}_{X} p(a)$ is true for $V(a)=k$ and false otherwise

In Case 3a

$a \mathbf{E}_{X} p(a)$ is true for $V(a)>h$ and false otherwise

$a \mathbf{D}_{X} p(a)$ is always false

$a \mathbf{S}_{X} p(a)$ is true for $V(a) \leq k$ and false otherwise

In Case 3b

$a \mathbf{E}_{X} p(a)$ is true for $V(a)>h$ and false otherwise

$a \mathbf{D}_{X} p(a)$ is true for $V(a)<l$ and false otherwise

$a \mathbf{S}_{X} p(a)$ is true for $l \leq V(a) \leq h$ and false otherwise.

It is straightforward if a little tedious to check that the axioms are verified in such a model. The important ones to check are the Axioms of Contrariety and Monotonicity, and they are verified. 


\section{Precedent}

To my knowledge there has been very little philosophical discussion of the logical principles of excess and sufficiency. The nearest to an exception is in Alexius Meinong's late ethical writings, ${ }^{5}$ where Meinong attempts to line up deontic categories, including those found in the deontic square of opposition, with linearly ordered values. Meinong's focus and interest are different from ours, but he is clearly fishing in the same pond: he connects linear series with the ideas of "too little" and "too much", he discusses polar opposites and squares of opposition, and he envisages various different kinds of value, not just ethical, but also economic, as sustaining analogous considerations. ${ }^{6}$

\section{Literature}

Agency (2015), Royal Navy Heroes of World War One Were Underage, Records Reveal, https://www.telegraph.co.uk/news/uknews/defence/11452252/Royal-Navy-heroes-of-World-War-One-were-underage-records-reveal.html (date of access: 15.09.2020).

Sajama S. (1988), Meinong on the Foundations of Deontic Logic, "Grazer Philosophische Studien" 32, s. 69-81.

106 Schubert-Kalsi M.-L. (1996), Alexius Meinong's Elements of Ethics, Kluwer, Dordrecht.

Simons P. (2012), Approaching the Modal Hexagon, “Logica Universalis” 6, s. 109-118.

Summary: The Logic of Excess

Statements such as 'This house is too expensive for me to buy', 'Jim is old enough to join the Navy', and similar and related statements, have to do with excess and sufficiency. They are connected in meaning systematically enough to sustain their own local logic. The chief difficulty in formulating this logic is that of discerning the best way to represent such statements and to take account of the loose fit between a strict logic and ordinary ways of speaking about excess and its cognates. This paper examines this hitherto virtually unexplored area, providing examples, analysis, axioms and models.

Keywords: excess, sufficiency, opposition

Streszczenie: Logika nadmiaru

Zdania takie jak "Ten dom jest dla mnie zbyt drogi", ,Jim ma wystarczająco dużo lat, aby wstąpić do marynarki" i podobne dotyczą nadmiaru

${ }^{5}$ Thanks to Kevin Mulligan for pointing this out.

${ }^{6}$ The rather sparse literature to this topic includes notably (Sajama 1988) and (Schubert-Kalsi 1996). 
i wystarczającej ilości. Są one na tyle powiązane znaczeniowo, że odpowiadać im może ich własna logika. Podstawowa trudność przy formułowaniu logiki nadmiaru polega na dostrzeżeniu najlepszego sposobu reprezentowania takich zdań oraz wyjaśnienie luźnego związku między ścisłą logiką a zwykłym sposobem mówienia o nadmiarze oraz o związanych $\mathrm{z}$ nim pojęciach. $\mathrm{W}$ artykule tym badam praktycznie niespenetrowany do tej pory obszar, podaje przykłady, analizy, aksjomaty i modele.

Słowa kluczowe: nadmiar, wystarczająca ilość, przeciwieństwa 